\title{
Are men and women-economists evenly distributed across research fields? Some new empirical evidence
}

\author{
Juan J. Dolado • Florentino Felgueroso • \\ Miguel Almunia
}

Received: 24 May 2010 / Accepted: 2 May 2011 / Published online: 25 May 2011

(C) The Author(s) 2011. This article is published with open access at SpringerLink.com

\begin{abstract}
This paper analyzes the gender distribution of research fields in economics based on a new dataset of almost 1,900 researchers affiliated to top-50 economics departments in 2005, as ranked by Econphd.net website. We document that women are unevenly distributed across fields and test some behavioral implications from theories underlying such disparities. Our main findings are that the probability that a woman works on a given field is positively related to the share of women already working on that field (path-dependence), and that this phenomenon is better explained by women avoiding male-dominated fields than by men avoiding female dominated fields. This pattern, however, is weaker for younger female researchers who spread more evenly across fields.
\end{abstract}

Keywords Men and women-economists · Research fields · Gender segregation · Path-dependence $\cdot$ Multinomial logit models

\footnotetext{
We thank the Editor and three referees for constructive criticisms on previous versions of the paper. We are also grateful to Manuel Arellano, Jorge Durán, Andrew Oswald, and participants at several seminars and conferences for many helpful comments. Andrea Cerasa and Sandro Díez-Amigo provided excellent research assistance. Financial support from the European Commission under the project The Economics of Education and Education Policy in Europe (MRTN-CT-2003-50496), the Spanish Ministry of Education (grant Consolider-Ingenio 2010) and Consejería de Educación de la Comunidad de Madrid (grant Excelecon) is gratefully acknowledged.
}

\author{
J. J. Dolado $(\varangle)$ \\ Universidad Carlos III, CEPR \& IZA, Madrid, Spain \\ e-mail: dolado@eco.uc3m.es \\ F. Felgueroso \\ Universidad de Oviedo \& FEDEA, Oviedo, Spain
}

M. Almunia

U.C. Berkeley, Berkeley, USA 


\section{JEL Classification A11 $\cdot$ J16 $\cdot$ J70}

In the 1960s and 1970s a large fraction of (the relatively small representation of) female economists chose "women's topics- female labor supply behavior, gender discrimination, economics of the family, etc. The fraction is smaller today, but such topics are still disproportionate among new female Ph.D.s" [Daniel S. Hamermesh (2005)]

\section{Introduction}

Female participation in economics research has surged during the last decades. For example, the percent of doctoral degrees awarded to women-economists in the US increased from 7\% in 1970 to almost 27\% in 2000 (se, e.g., Ginther and Kahn 2004). Yet, little is known about whether this increase in female participation has been evenly distributed across the different fields of economics research. Nonetheless, as illustrated by the item quoted in the paper's epigraph, it is commonly believed that research undertaken by women-economists is mostly concentrated in some areas, generally coined as "female" fields. This segregation phenomenon has been well documented in other scientific disciplines but still not in economics. ${ }^{1}$

The goal of this paper is precisely to examine whether that perception can be substantiated by empirical evidence. In particular, we have two questions in mind: Are there significant and persistent gender differences in the choice of research fields in economics? and, if so, Why do they exist?

Following the initiative by the American Economic Association (AEA) of setting up a Committee on the Status of Women in the Economics Profession (CSWEP) in the early seventies, ${ }^{2}$ there is a growing literature, especially in the US, documenting how the prospects of female academic economists have developed over time, in parallel with women making great inroads in the economics profession. ${ }^{3}$ However, as pointed out before, the existence of gender differences in the distribution across specific areas of research in this discipline, and the reasons behind potential disparity has attracted much less attention. Indeed, the only related works that we are aware of are McDowell et al. (1999) and Boschini and Sjögren (2007) who analyze gender differences in co-authorship but not in research specialization. To the extent that choice of research fields may influence academic careers, analyzing the determinants of such choices may be helpful in understanding women's performance in economics in general.

Our paper contributes to fill this gap in two ways. First, we compile a new data set on fields in which research has been undertaken by male and female faculty members

\footnotetext{
1 For instance, there is ample evidence on female physicians being over-represented in pediatrics or obstetrics and under-represented in surgery or orthopedics. Likewise, female psychologists are over-represented clinical and environmental psychology and under-represented in neuropsychology; cf. Borden et al. (2007).

2 More recently, similar initiatives have been launched by other academic societies like, e.g., the European Economic Association, the Royal Economic Society and the Spanish Economic Association.

3 See, inter alia, Hansen (1991), Kahn (1993, 1995), McDowell et al. (1999); Booth et al. (2000); Ginther and Kahn (2004), and the references therein.
} 
affiliated to a large number of distinguished economics departments in 2005. Secondly, we use this data to test implications stemming from alternative behavioural theories which could potentially explain gender differences in this dimension. ${ }^{4}$ Specifically, we draw on the detailed information available at the Econphd.net website (econphd.econwiki.com) on rankings of economics departments in the world according to the quality of their research in a wide range of fields. ${ }^{5}$ These rankings are among the most substantial in scope: economics departments are ranked in an overall classification (All Economics), as well as in many (34) sub-fields, on the basis of the research quality of their faculties' publications in leading academic journals over 1993-2003. Journal selection and quality adjustment are based on the citation analysis developed in Kalaitzidakis et al. (2003). Focusing on the rankings related to All Economics, we have selected tenured-track and tenured faculty members (excluding adjuncts and visiting professors) in the top 50 departments (listed in the Appendix), out of which $74 \%$ are North-American while the remaining $26 \%$ are European. ${ }^{6}$ Once the roster of economics faculty in these departments was identified, a detailed search on the personal websites of almost 1,900 researchers, out of which $15 \%$ are females, allowed us to retrieve information on their fields of specialization (using both JEL and Econphd.net codes) and other personal characteristics.

Secondly, after documenting that men and women-economists are represented differently across research fields in our sample, we analyze potential reasons for this disparity. In particular, we focus on testing the implications of several theories that would predict path dependence i.e., are women more likely to join fields in which the share of women is already high? The theories we discuss here range from genuine gender differences in preferences for research topics to gender segregation into certain sub-fields pushed by external factors (such as men avoiding female fields or women shying away from male fields), as well as different gender attitudes in highly competitive environments like academic research in top departments.

In this respect, a warning is required on the limitations of our data for some of the empirical exercises carried out throughout the paper. In particular, analyzing persistence features (path dependence) requires longitudinal data describing the developments over time of the number and gender of researchers in each field. However, since our data is a cross-section for 2005, attempts to analyze the "dynamics" of the gender distribution by field across different age cohorts based on a single snapshot are bound to suffer from selection biases. ${ }^{7}$ Some faculty members in the past may have either retired or moved to other departments outside the top 50 and to jobs outside acade-

\footnotetext{
4 We choose researchers in distinguished departments in order to isolate highly competitive environments where overt discrimination and inbreeding practices are absent. Note that, although choice of research subfield choice typically occurs in the second or third year of graduate school, these initial choices may change over researchers' careers, as we discuss in Sect. 2 where we document that researchers often have more than one field of research in economics.

5 Launched in 2003, Econphd.net is one of the best-known non-department websites in Economics. It is run at the University of Melbourne, Department of Economics, and the Economic Theory Centre.

6 Out of the top 50 economics departments, 35 are based in the US, 13 in Europe (including Israel), and 2 in Canada.

7 This is analogous to testing theories of firm behaviour using a cross-section of firms and trying to distinguish different behavioural patterns by age of firm from this cross-section.
} 
mia. Hence, there could be a large attrition bias in our sample which, unfortunately, is very complicated to address. In effect, reconstructing the actual composition of these departments over a period longer than 40 years becomes an insurmountable task: we would need data on different cohorts when they entered and left these departments. Getting this information is simply not feasible for such a long period of time and large number of departments. Admittedly, some of this flow data is available for a handful of Ivy League departments at the AEA membership directories (see Sect. 3.2) but that would restrict the scope of our study to a smaller group of researchers in this highly restricted category of institutions instead of the much larger number of researchers analyzed here. Moreover, since membership is voluntary, sample selection would still be present. Alternatively, one could use data on different cohorts of graduates in these departments but that would restrict the choice of fields to $\mathrm{Ph}$.D. dissertations and not to their subsequent research output.

As a result, our findings need to be taken with caution, unless one accepts the underlying assumption in our cohort-based analysis that mobility of academics outside the top 50 departments or out of the academia has not changed drastically the gender ratios across fields that we compute from the career path of academics in our 2005 snapshot. In this respect, we will report some fragmentary evidence below pointing out that this may not be a too far-fetched assumption.

With this big caveat in mind, our main findings can be summarized as follows. First and foremost, we document that there is gender segregation by field. Secondly, we find strong evidence of path dependence. Rather than being explained by men-economists avoiding "female" fields, tipping them to become even more "female", our evidence indicates that women avoid strongly male-dominated fields. We conjecture that this phenomenon could be possibly rationalized by gender differences in the propensity to compete since we find a negative correlation between the share of women in a given field and a proxy for the degree of competition in that field. This last variable, labeled "quality" index, is measured by the proportion of papers in a given field which end up being published in the most prestigious general interest and field journals. Yet, these segregation patterns seem to be slowly disappearing among women-economists who graduated in the last decade, pointing to behavioural changes or shifts in preferences.

The rest of the paper is organized as follows. In Sect. 2 we discuss how conventional and more recent theories on discrimination and segregation can explain the main stylized facts of gender differences in research fields in economics, as well as draw several testable implications of these theories. Section 3 describes the dataset we compile and summarizes some salient features of the distribution of men- and women-economists across fields of specialization, including some cohort-based analysis of how gender segregation by field has evolved. Section 4 presents econometric evidence about the previous implications based on both aggregate and individual data. Finally, Sect. 5 concludes. An Appendix with three sections offers a detailed description of the data and some supplementary material.

\section{Theories on research-field choices by women-economists}

There is an extensive empirical literature showing that large gender earnings gaps prevail in competitive high-ranking positions (see, e.g., Blau and Kahn 2000), as 
well as documenting that the allocation of high-profile jobs remains largely favorable to men (see, e.g., Bertrand and Hallock 2001; Black and Strahan 2001). Since academic positions could be considered as generally akin to this type of occupations-all requiring large human capital investments-some of the theories used to explain these facts could be relevant for our topic at hand. We broadly classify them into five categories to then discuss their plausibility in our specific setup.

The first two explanations are quite well known. One rests on self-selection (see Polachek 1981). The insight is that, even if one were to assume that the distribution of abilities is identical for men and women, the fact that the latter may face career interruptions (e.g., due to child bearing or some other family-care related issues) hampers their access to those high-quality jobs. Thus, on the basis of expectations about these inactivity periods, women may self-select into lower profile jobs where, in contrast to top occupations, the penalty for career breaks is smaller. This theory has been used to explain gender differences across disciplines, e.g., in humanities and engineering (see Borden et al. 2007) but it is less clear that it may play a relevant role in explaining differences in the distribution across fields within a given discipline (economics). The other one relates to "Becker-type" discrimination in the workplace, leading to different treatment of equally able men and women as long as perfect competition does not prevail in product/labor markets (see, e.g. Goldin and Rouse 2000; Black and Strahan 2001). Again this explanation does not look plausible in our setup of highly competitive research activities carried out in distinguished departments.

The third explanation, labeled preference persistence (in short, $P P$ ) is related to differences in preferences: women would choose different jobs than men because they are genuinely interested in different activities. In our setup, it would imply that women always prefer certain topics to others irrespectively of path-dependence issues. The fourth one relies on theories of segregation as a cause of social exclusion (SE, henceforth), mostly applied to ethnic groups. They are inspired by Schelling's (1971) and Loury's (1977) well-known arguments about how asymmetries in whites' bias against living with blacks_relative to blacks' bias against living with whites - can lead neighbourhoods to tip toward all Black, once the fraction of blacks exceeds a certain threshold. Applying this theory to our setup might mean than male researchers avoid fields if they get too female, or vice versa.

More recently, a related rationalization of the under-representation of women in high-skilled occupations has been proposed which may also play a role in our specific setup (see, Gneezy and Rustichini 2004). The basic finding of experimental research on this issue is that women, selected to be equally competent as men, under-perform in mixed-gender groups relative to single female groups. Men's performance, by contrast, does not significantly change between these groups. Hence, their main implication to be drawn is that women only dislike competition when it is against men. In the sequel, this theory will be labeled as gender differences in competition (GDC henceforth). ${ }^{8}$

8 The available experimental evidence confirms that, while there are no significant differences in men's
and women's performances in noncompetitive environments (e.g., under a fixed-rate payment scheme for 
As a result, female academic economists may skip male-dominated fields to avoid mixed-gender competition.

Our prior belief is that, taken in isolation, none of the previous explanations can be used to interpret the patterns of gender differences in the choice of research fields documented below. Issues related to women's self-selection and taste discrimination for academic candidates competing for positions in top departments, with similar publication records (scores) and other valuable skills, should be much less relevant than in other segments of the labor market where meritocracy is not so strong. Consequently, it is very unlikely that women are driven by external factors (e.g., supervisors' advice to study some specific topics in their dissertations) in choosing different fields than men. In such a strongly competitive environment, research excellence rules in the allocation of faculty positions and tenure awards, like in tournament setup.

However, it is highly plausible that in the 1970 s, when females started to represent a significant fraction of doctorates in economics, perceptions that discrimination and segregation were the most relevant gender-related problems to be addressed, pushed women toward these topics. Once the initial clustering of women-economists in gender/social fields took place, subsequent female cohorts may have followed a similar choice pattern because of either of these three reasons: (a) women remain interested in the same topics, as implied by $P P$, (b) women dislike working on other topics where male researchers are predominant, as in $G D C$, or (c) men avoid female fields, as predicted by $S E$.

These considerations lead us to consider the following testable hypothesis-split into three cases-concerning the choice of research fields by women-economists:

\section{Hypothesis 1}

\section{(Hla) Under PP, women are genuinely interested in some fields irrespectively of their past gender composition. \\ (H1b) Under SE, men avoid fields where the fraction of women exceeds a certain threshold. \\ (H1c) Under GDC, women avoid fields where the fraction of men exceeds a certain threshold.}

As will be discussed in Sect. 4, H1a is akin to testing for persistence solely explained by field fixed effects in cohort regression models. By contrast, both H1b and H1c lead to path dependence (i.e., women's share in a field is positively correlated with past female share) after controlling for field fixed effects across cohorts, that is, independent of the fact that women may prefer some fields over others. Yet, notice that the mechanisms behind path dependence differ between the two hypotheses. Under $S E$,

\footnotetext{
Footnote 8 continued

completing a given task in a given period), the average performance of men significantly increases relative to women's in competitive and uncertain environments (e.g., in winner-takes-it-all tournaments where the fixed-rate payoff scheme is replaced by another one where only the participant completing the largest number of tasks is paid proportionally to the output). Interestingly, however, it is also found that women have a higher chance of developing their skills and interests when shielded from competition with men. That is, women's performance also increases relatively to noncompetitive setups when they compete only against women in single sex groups; cf. Gneezy et al. (2003), Niederle and Vesterlund (2007), and Gneezy et al. (2009), for a debate on this issue.
} 
H1b states that men will be those who avoid choosing female fields because, e.g., they may (subjectively) feel that female fields are stigmatizing or hamper their career prospects. Conversely, under $G D C$, women avoid male-dominated fields because they do not wish to compete with men. In either case, however, the final implication is higher gender segregation across fields.

Additionally, regarding $G D C$, it is important to notice that not all research fields may be equally competitive. For example, working on a fashionable/novel topic may have a higher impact in terms of top publications, prestige and tenure prospects for younger researchers than working in a well-trodden and populous field where major contributions are less likely. To the extent that "high quality" fields attract more competitive male researchers, a direct prediction of women's dislike for mixed-gender competition would be lower female prevalence in highly competitive fields. This leads to the additional testable hypothesis:

Hypothesis 2 (H2): Under GDC, there is a negative correlation between degree of competition and the share of women-economists in a given field.

\section{Data description}

Data are collected from the personal websites of faculty members of the top-50 economics departments in 2005 as listed in Econphd.net (All Economics category; see Appendix A). In this fashion, we extract information on the research fields of 1876 academics out of which 284 are females (15.1\%). Using JEL codes in publications, fields were assigned on the basis of the main bodies of published research. For some of the analysis, in line with Boschini and Sjögren (2007), we grouped the disaggregate JEL codes in 10 main fields, with the last one capturing "other fields" ("Other" in short). In some other instances, where less aggregation is more convenient, we use finer lists of either 20 JEL fields or 34 sub-fields on which Econphd.net offers information about the quality of publications (see Appendix B for details on aggregation procedures).

At this stage, it is important to stress that researchers often have publications in different fields. Interestingly we find that, on average, men and women report almost two fields of research (male avg. $=1.88$, female avg. $=1.86$ ). In the sequel, we will refer to this unit of analysis as Researcher-fields (henceforth RFs) to differentiate it from individual researchers for whom we identify a single main field of specialization as the one in which they have more publications. ${ }^{9}$

\subsection{Descriptive statistics and gender segregation by field}

Table 1 presents the gender distribution of researchers and RFs across fields in our dataset, using the coarser aggregation of 10 JEL fields.

\footnotetext{
9 When RFs are used as unit of analysis, the distributions can be either computed giving each RF observation the same weight (unweighted) or alternatively weighting the observation by the factor: 1/\# researcher's fields (weighted).
} 
Table 1 Gender distribution of researchers in top 50 departments across JEL 10 fields

\begin{tabular}{|c|c|c|c|c|c|c|}
\hline Field & $\begin{array}{l}\text { (1) } \\
\text { No. of researchers }\end{array}$ & $\begin{array}{l}(2) \\
\text { Women } \\
(\%)\end{array}$ & $\begin{array}{l}(3) \\
\text { Men } \\
(\%)\end{array}$ & $\begin{array}{l}\text { (4) } \\
\text { No. of RFs }\end{array}$ & $\begin{array}{l}(5) \\
\text { Women } \\
\text { (Weighted, \%) }\end{array}$ & $\begin{array}{l}(6) \\
\text { Women } \\
\text { (Unweighted, \%) }\end{array}$ \\
\hline 1. Econometrics & 186 & 9.2 & 10.0 & 393 & 9.1 & 8.1 \\
\hline 2. Micro/Theory & 382 & 4.2 & 23.2 & 629 & 5.1 & 5.3 \\
\hline 3. Macro & 193 & 5.5 & 11.6 & 422 & 5.6 & 5.4 \\
\hline 4. International & 131 & 4.5 & 7.4 & 239 & 4.8 & 5.6 \\
\hline 5. Public Econ. & 167 & 12.2 & 8.3 & 366 & 14.1 & 13.3 \\
\hline 6. Labour & 131 & 18.2 & 5.0 & 338 & 18.4 & 20.4 \\
\hline 7. I.O. & 146 & 14.3 & 6.6 & 299 & 15.4 & 14.4 \\
\hline 8. Growth/Dev. & 137 & 7.8 & 7.2 & 285 & 10.3 & 8.3 \\
\hline 9. Economic Hist. & 56 & 10.8 & 1.6 & 103 & 5.9 & 6.9 \\
\hline 10. Other & 342 & 13.3 & 19.1 & 592 & 11.3 & 12.3 \\
\hline Total & 1876 & 100 & 100 & 3666 & 100 & 100 \\
\hline
\end{tabular}

Column (1) reports the overall number of researchers (assistant/lecturer, associate/reader and full professors, where the proportion of tenured professors reaches $70.1 \%$ ), while columns (2) and (3) display the female and male distribution of researchers across fields, respectively. Likewise, columns (4)-(6) show similar information this time regarding RFs (weighted and unweighted). In both cases, the categories with the largest female shares are Labor Economics, I.O., Public Economics and Other, whilst Micro/Theory, International and Macro are those where women are less prevalent. Despite the small number of fields, a Kolmogorov-Smirnov test rejects the null of equality of the two distribution at $10 \%$ significance level ( $p$-value $=0.062$ ).

At a more disaggregate level, Figs. 1 and 2 plot the fraction of (weighted) female RFs in each field (i.e., number of female RFs in a field as a fraction of total number of RFs in that field) according to the more detailed lists of 20 (JEL) and 34 (Econphd) sub-fields, respectively. ${ }^{10}$

The findings are fairly similar to those reported in Table 1. According to Fig. 1 (20 subfields), Health, Education and Welfare and Labor and Demographic Economics are the most popular subfields among women (20-25\%) while Mathematical Economics, Agricultural Economics and Other Special Topics are among the least popular (below 10\%). As for Fig. 2 (34 subfields), Wages and Inequality (including Gender Discrimination), Education, Health and Demographics, Labor, and Social Choice and Public Goods are at the top of female choices whereas Mathematical Economics, Fluctuations and Business Cycles and Agricultural Economics are at the bottom.

\footnotetext{
10 Again, Kolmogorov-Smirnov tests reject the null of equal distributions in these two cases with $p$-values of 0.028 and 0.023 , respectively.
} 


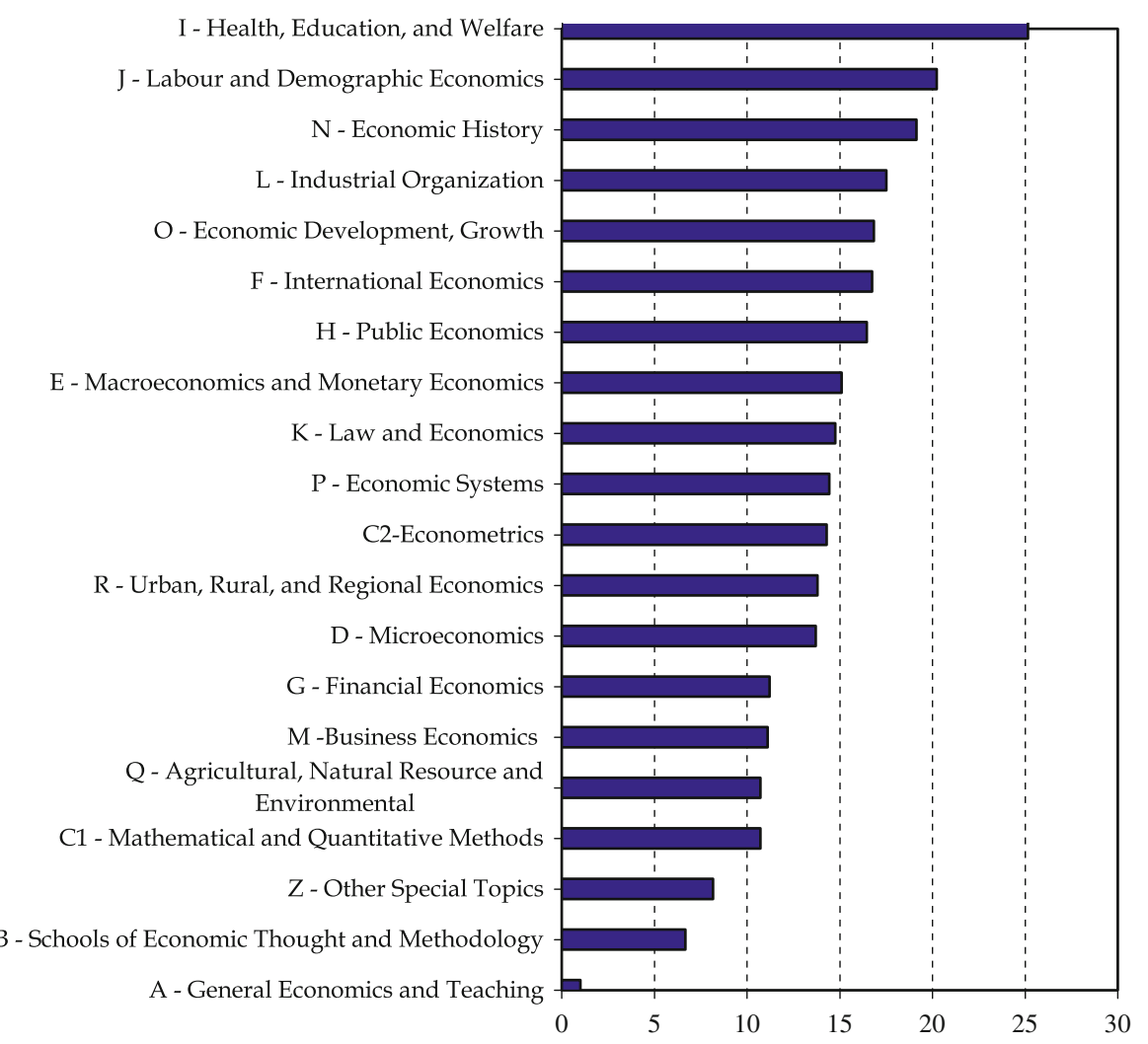

Fig. 1 Proportion of women in top 50 departments in each field (JEL 20 fields)

\subsection{Ph.D. cohorts}

In this section, we analyze the gender distribution of researchers and RFs in our dataset distinguishing by $\mathrm{Ph} . \mathrm{D}$. cohort. To reduce data noise, we often aggregate annual cohorts in terms of either nine 5-year spells or four 10-year spells.

Figure 3 displays the distribution of researchers by Ph.D. cohorts (5-year spells), as of 2005 whereas Table 7 in Appendix B shows the number of men and women by (10-year) cohort for each of the JEL-10 fields. As can be observed, more than $25 \%$ of women-economists graduated in 2001-2005 while less than $2 \%$ did in 19711975. Given the implicit non-random truncation in our sample, it is not surprising that the percentage of females is so low in the earlier cohorts. Yet, the increasing pattern over cohorts is a common feature in all other studies that use genuine longitudinal data, allowing for entries and departures, instead of the cross-section data we use here (see, e.g., Ginther and Kahn 2004). By contrast, the distribution for men-economists exhibits a flatter pattern, with a quite smaller increase between the older and younger cohorts.

Figure 4 shows the relationship between the share of women in a field at a given cohort and the share of women in that field in the previous (10-year) cohort. We can 


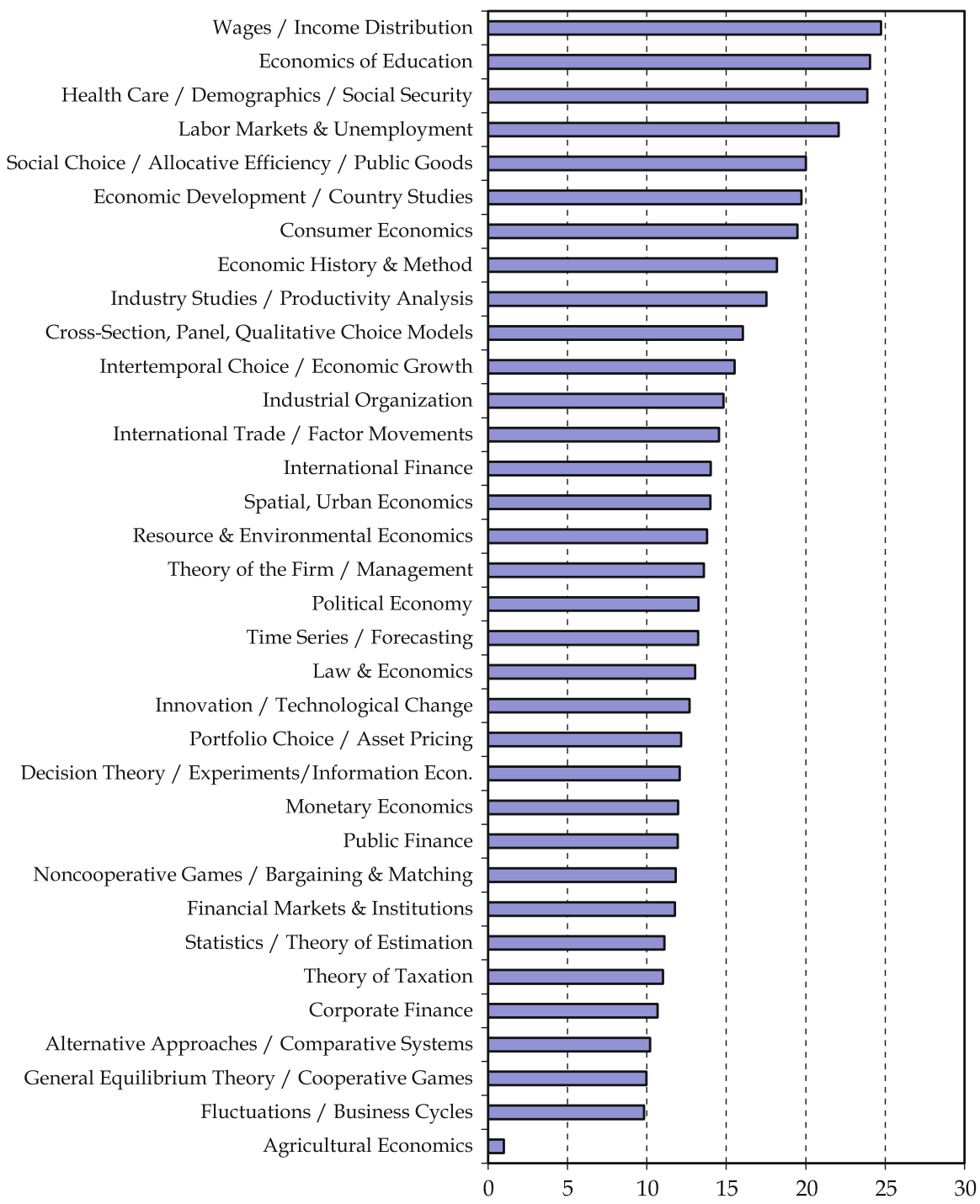

Fig. 2 Proportion of women in top 50 departments in each field (Econphd 34 subfields)

observe a strong positive relationship for Labour and Demographic Economics, and Health Education and Welfare, i.e. the two fields with higher female shares in the older cohorts. By contrast, though also positive, the relationship is much weaker in other fields, like Mathematical and Quant. Methods or Econometrics, where the earlier female shares were low.

At this stage we argue that, despite clear attrition in our sample, the cohort patterns just described above are not just simply the outcome of using a single snapshot of the roster of economics faculty in these top departments. This can be checked using data available at the AEA membership directory to obtain information on fields of specialization (10 JEL fields) and faculty lists from 10 Ivy League economics 


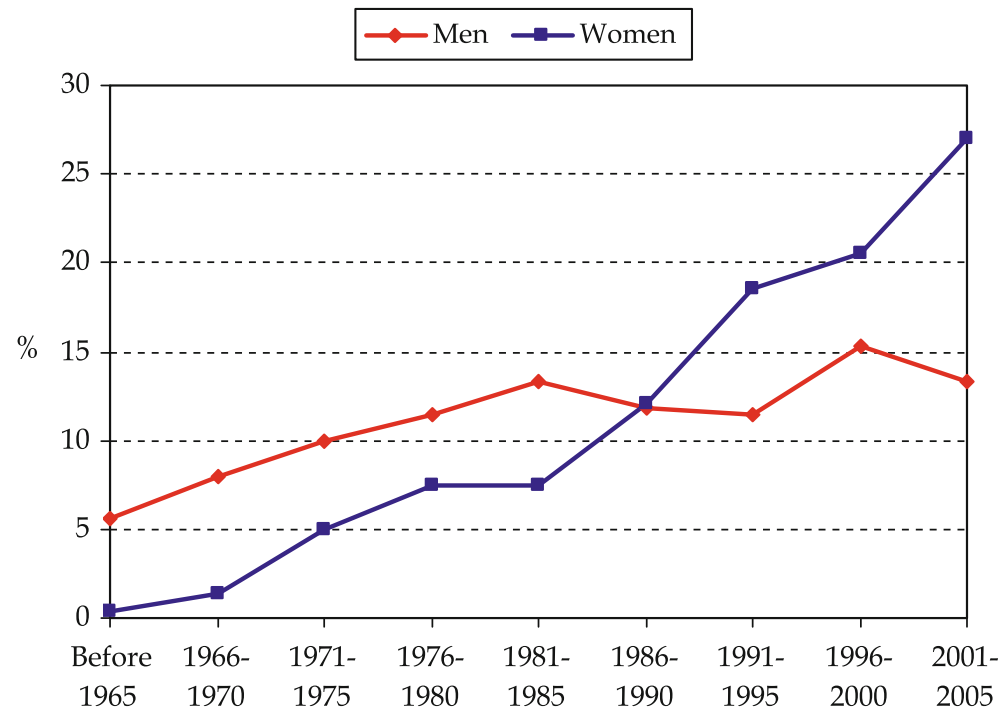

Fig. 3 Distribution of faculty members by $\mathrm{Ph} . \mathrm{D}$ cohort and gender

\begin{tabular}{ll|}
$\longrightarrow$ Total & $\rightarrow$ Mathematical and Quantitative Methods \\
$\longrightarrow$ Econometrics & $\rightarrow-$ Labour and Demographic Economics \\
$\longrightarrow$ Health, Education, and Welfare &
\end{tabular}

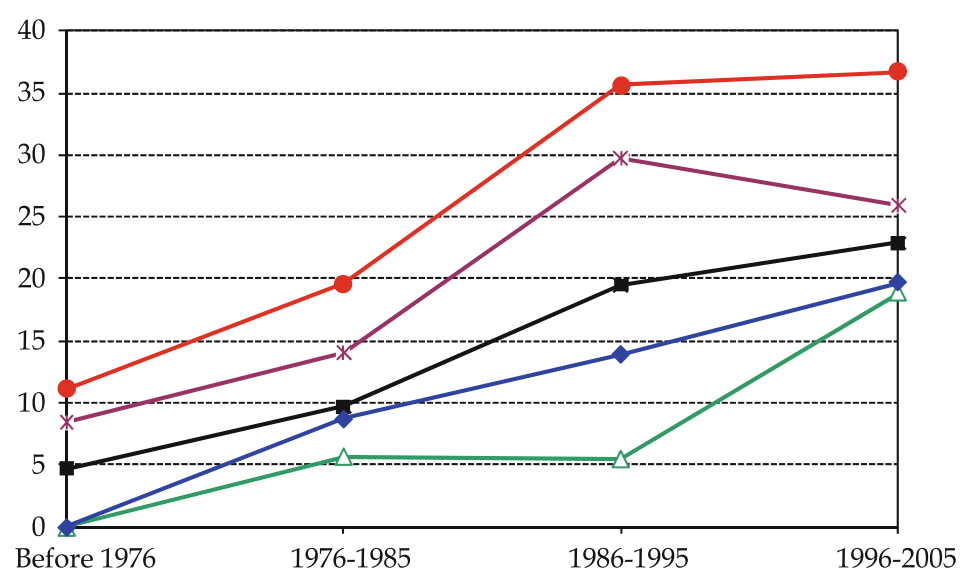

Fig. 4 Share of women (\%) in top 50 departments by field and cohort

departments in the US for 1983, 1993 and 2003. ${ }^{11}$ The number of researchers in these departments is 206 (1983), 341 (1993) and 329 (2003). Figure 5 plots the same information as depicted in Fig. 4 for these three years using this genuine longitudinal

\footnotetext{
11 The data correspond to: Berkeley, Chicago, Harvard, MIT, NYU, Northwestern, Penn, Princeton, UCLA and Yale. We thank Galina Hale for making them available to us.
} 


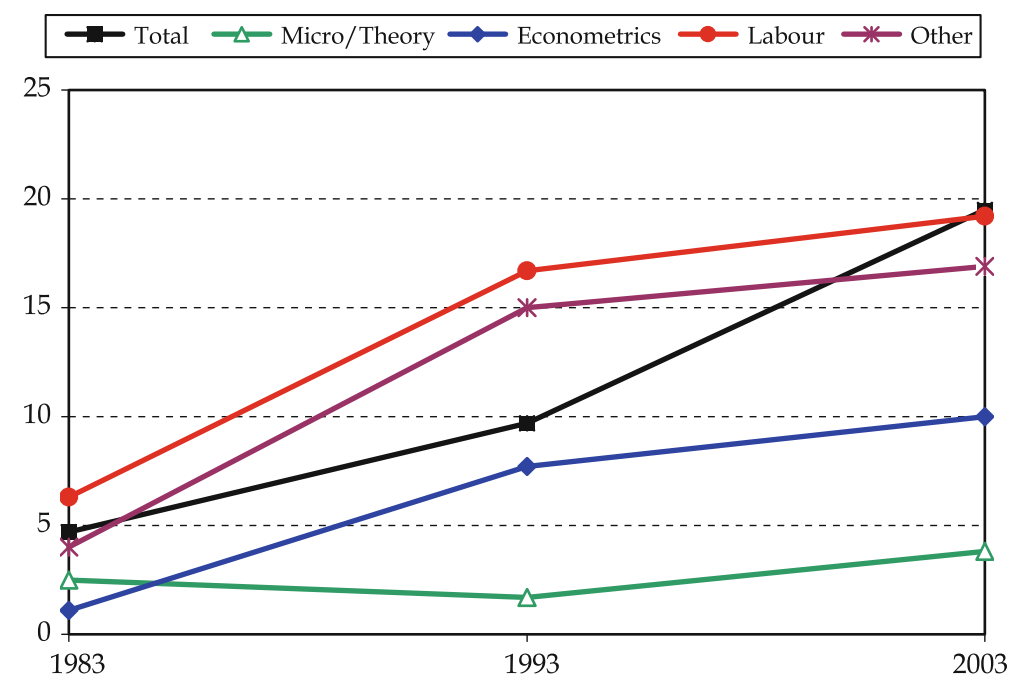

Fig. 5 Share of women (\%) in 10 top US departments by field and year

dataset and the closer fields to those depicted before. Although the female proportions are lower, in general they exhibit similar patterns to those documented above.

Overall, we interpret this preliminary evidence as providing support for path dependence. However, since it can just be reflecting that women prefer certain field for some unrelated reasons, regression analysis will be used in Sect. 4 to help us identify which is the more appropriate interpretation of these findings.

\subsection{Cohort changes in gender segregation by field}

So far we have presented descriptive evidence documenting the distribution of the female share by field in our dataset and how it varies across different cohorts. In order to explore the determinants of these changes, we next provide some further analysis about how gender segregation by field has evolved making use of the well-known Duncan and Duncan segregation index (S index, henceforth) across the different RFs over 10-year cohorts. ${ }^{12}$

When the four 10-year cohorts are pooled, the value of the overall $\mathrm{S}$ index is in the range $11-13 \%$, depending on whether RFs observations are weighted or not. This is a much lower value than the corresponding indexes reported by Dolado et al. (2001, 2004) for occupational gender segregation in the population with college education in the US (around 35\%) and in the EU (around 38\%). Moreover, whereas the S value

\footnotetext{
12 The $\mathrm{S}$ index is defined as $\mathrm{S}_{\mathrm{c}}=0.5 \Sigma_{i}\left|\mathrm{~m}_{\mathrm{ic}}-\mathrm{f}_{\mathrm{ic}}\right|$, where $\mathrm{m}_{\mathrm{ic}}\left(\mathrm{f}_{\mathrm{ic}}\right)$ is the proportion of male (female) faculty members in field $i$ for Ph.D. cohort $c$. This index, expressed as a percent, can be loosely interpreted as the proportion of women (men) who have to "trade" fields with a man (woman) for both sexes to be represented in all fields in proportion to their representation in the whole system. A value of $0 \%$ indicates that the distribution of men and women across fields is the same, while a value of $100 \%$ indicates that women and men work in completely different fields.
} 
does not decrease by much between the 1976-1985 and 1986-1995 cohorts (from 18.2 to $15.7 \%$ ), it falls to $10.2 \%$ for the younger cohort (1996-2005). Following the increasing participation of female graduates in the academic labor market, this lower degree of segregation by field may reflect a change in previously observed patterns.

To analyze the extent to which the reported changes in segregation are due to genuine changes in female choices of research fields or to variations in the weight of fields where they have traditionally worked, we adapt to our specific framework of cohorts Blau, Simpson and Anderson's (1998, BSA henceforth) decomposition method of the change in the $\mathrm{S}$ index over time. This decomposition yields a breakdown of the total change in the $S$ index between two consecutive 10-year cohorts into two effects: (a) a sex composition effect within fields, holding constant the weights of fields, and (b) a field weight effect due to changes in the field mix, holding constant the sex composition within fields.

The BSA decomposition works as follows. Denoting by $\mathrm{M}_{\mathrm{ic}}\left(\mathrm{F}_{\mathrm{ic}}\right)$ the number of male (female) researchers in field $i$ and cohort $c$, the female and male shares by cohort and field are defined as $\mathrm{p}_{\mathrm{ic}}=\mathrm{F}_{\mathrm{ic}} /\left(\mathrm{M}_{\mathrm{ic}}+\mathrm{F}_{\mathrm{ic}}\right)$ and $\mathrm{q}_{\mathrm{ic}}=\mathrm{M}_{\mathrm{ic}} /\left(\mathrm{M}_{\mathrm{ic}}+\mathrm{F}_{\mathrm{ic}}\right)$, respectively, whereas the field weight is defined as $\alpha_{i c}=\left(M_{i c}+F_{i c}\right) / \Sigma_{i}\left(M_{i c}+F_{i c}\right)$. Aggregating over all fields, the $\mathrm{S}$ index for cohort c can be expressed as $\mathrm{S}_{\mathrm{c}}=0.5 \Sigma_{\mathrm{i}} \mid\left(\mathrm{q}_{\mathrm{ic}} \alpha_{\text {ic }} / \mathrm{q}_{\text {ic }} \alpha_{\text {ic }}\right)-$ $\left(\mathrm{p}_{\mathrm{ic}} \alpha_{\mathrm{ic}} / \mathrm{p}_{\mathrm{ic}} \alpha_{\mathrm{ic}}\right) \mid$. Let $\mathrm{Scc}^{\prime}$ denote the segregation index computed with female and male shares corresponding to cohort $\mathrm{c}$ and field weights corresponding to cohort $\mathrm{c}^{\prime}$. Then, using the notation $\mathrm{c}, \mathrm{c}^{\prime}=0,1$, where " 1 " denotes the younger Ph.D. cohort and " 0 " the older cohort, the difference between $\mathrm{S}_{1}$ and $\mathrm{S}_{0}$ (or $\mathrm{S}_{11}$ and $\mathrm{S}_{00}$ with this new notation) satisfies:

$$
\mathrm{S}_{1}-\mathrm{S}_{0}=\left(\mathrm{S}_{10}-\mathrm{S}_{00}\right)+\left(\mathrm{S}_{11}-\mathrm{S}_{10}\right)
$$

The first term in the RHS of (1) captures changes due to the sex composition effect i.e., the change in the index between cohorts 1 and 0 that would have occurred if the weight of each field had remained fixed at its level for cohort 0 , while the second term yields the field weight effect i.e., the change in the index if the gender shares had remained invariant at the level of cohort 1.

Table 2 displays the results of using (1) to decompose changes in $\mathrm{S}$ over the last three 10-year-cohorts across 20 and 34 fields, respectively. For illustrative purposes, Table 8 in Appendix $\mathrm{C}$ shows the gender shares and field weights used in the computation of the decomposition using 20 fields. Since the results with the un-weighted and weighted versions of the $\mathrm{S}$ index are similar, we only report results for the latter in this table.

The main conclusion to be drawn from Table 2 is that the contribution of the sex composition effect is much larger than that of the field weight effect for the two cohorts after 1986 whereas they are more balanced for the earlier cohort. Indeed, the RHS panel of Table 8 in Appendix $C$ shows that the field weights $\left(\alpha_{i}^{\prime} \mathrm{s}\right)$ have remained fairly stable over cohorts -with a few exceptions like Econometrics and Microeconomics which have increased their weights by almost $4 \mathrm{pp}$. On the contrary, the left panel shows that female shares in many fields have increased substantially. This is particularly the case of fields like Health, Education and Welfare, I.O., Business Economics, 
Table 2 BSA decomposition of changes in $\mathrm{S}$ index

\begin{tabular}{|c|c|c|c|c|c|c|c|c|c|}
\hline & \multicolumn{3}{|c|}{ 1976-1985/before 1976} & \multicolumn{3}{|c|}{ 1986-1995/1976-1985 } & \multicolumn{3}{|c|}{ 1996-2005/1986-1995 } \\
\hline & $\begin{array}{l}\text { Sex } \\
\text { Comp }\end{array}$ & $\begin{array}{l}\text { Field } \\
\text { Weight }\end{array}$ & Total & $\begin{array}{l}\text { Sex } \\
\text { Comp }\end{array}$ & $\begin{array}{l}\text { Field } \\
\text { Weight }\end{array}$ & Total & $\begin{array}{l}\text { Sex } \\
\text { Comp }\end{array}$ & $\begin{array}{l}\text { Field } \\
\text { Weight }\end{array}$ & Total \\
\hline UDDS (20) & -2.4 & -1.5 & -3.9 & -2.4 & -0.2 & -2.6 & -5.1 & -0.5 & -5.6 \\
\hline WDDS (20) & -1.9 & -1.7 & -3.7 & -2.9 & -0.2 & -3.3 & -4.8 & -1.0 & -5.8 \\
\hline UDDS (34) & -2.6 & -2.1 & -4.3 & -3.3 & -0.2 & -3.5 & -5.0 & -1.2 & -6.2 \\
\hline WDDS (34) & -2.8 & -1.7 & -4.5 & -3.70 & -0.3 & -4.0 & -5.5 & -1.3 & -6.8 \\
\hline
\end{tabular}

UUDS and WDDS denote the un-weighted and weighted version of the $\mathrm{S}$ index; the numbers in parentheses are the number of fields

and Growth/Development where the female shares $\left(p_{\mathrm{i}}^{\prime} \mathrm{s}\right)$ have increased by more than $20 \mathrm{pp}$.

\section{Econometric evidence}

To test more formally the hypotheses posed in Sect. 2, we use two alternative econometric approaches. The first one relies upon aggregating information at the level of cohorts and fields (therefore ignoring the distribution of individual researchers across fields). The second one focuses on choices of fields at the individual level.

\subsection{Aggregate analysis across cohorts and fields}

We start by analyzing the aggregate determinants of the gender composition across fields and cohorts. To do so, controlling for field and cohort fixed effects, we regress the share of female RFs in each subfield (34) and 5-year cohorts (8), denoted by $F_{f c}$, on relevant covariates related to the various hypotheses. These covariates are the proportion of females in a given subfield in all previous cohorts, denoted by $F_{f c-\ell}$, and the degree of competition in that subfield proxied by its quality index, $Q_{\mathrm{fc}}$. This index is constructed as the ratio between the number of papers in a given field which are published in the list of 30 journals provided by Kalaitzidakis et al (2003, Table 2, using the weights in reported in their Table 1 for the quality of journals) and the (weighted) number of RFs in that field and cohort. ${ }^{13}$ Thus, this quality index for a field will be equal to 1 if all the RFs in that field get published in the selected list of journals and 0 if none gets published in those journals. The average quality index across fields is 0.273 (s.d. = 0.251). Figure 6 in Appendix B plots that average field quality index for each of the 34 fields.

Specifically, the regression model we consider is as follows:

$$
F_{f c}=\beta_{f}+\beta_{c}+\beta_{1} Q_{f c}+\beta_{2} F_{f c-\ell}+\varepsilon_{f c},
$$

\footnotetext{
13 The journal weights in Table 1 of Kalaitzidakis et al. (2003) correspond to 1993-2002. In the absence of similar weights for previous decades, we kept these weights fixed throughout all the half-decade cohorts, re-weighting them when a journal did not exist yet.
} 
where $\beta_{\mathrm{f}}$ and $\beta_{\mathrm{c}}$ are field and cohort fixed effects, and the error terms, $\varepsilon_{f c}$, are assumed to be i.i.d. across cohorts/fields. ${ }^{14}$ Accordingly, H1a $(P P)$ would imply that $\beta_{2}=0$, once we condition for field and cohort fixed effects. Conversely, either H1b (GDC) or H1c $(S E)$ imply $\beta_{2}>0$. The issue of how to distinguish between these two last hypotheses will be discussed in the next subsection. In turn, $\mathrm{H} 2$ implies that $\beta_{1}<0$. Further, given that the evidence shown in Sect. 3.3 pointed out to a changing pattern for the last cohort (1996-2005), we test this break by including interaction terms of $Q_{f c}$ and $F_{f c-\ell}$ with the indicator variable, 1(96-05). Finally, to account for possible variations in the nature of fields (e.g., labour has got more psychological and sociological through time) we also allow for interactions of the field and cohort fixed effects.

Column (1) in Table 3 reports the estimated coefficients in regression (2) without any interaction terms. We find strong statistically significant effects of both the quality index of the field and the past share of women in that field in all previous cohorts on the corresponding fraction of women. The higher the quality index of a given field, the lower its female share, so that a rise of this index in one s.d. ( $0.251 \mathrm{pp})$ reduces the female share by almost $0.13 \mathrm{pp}$. Likewise, an increase of $1 \mathrm{pp}$ in the past share of women in a given fields gives rise to a rise of $0.55 \mathrm{pp}$ in the current female share. Since we are controlling for field fixed-effects, in principle we interpret this evidence as an indication of path-dependence. Yet, given the large size of the coefficient on the past female share, we cannot rule out completely the omission of some unobserved characteristic in our specific sample of researchers affiliated to highly competitive departments. Notwithstanding this, one preliminary conclusion of the above results is that they yield some support to $\mathrm{H} 1$ (b and c) and $\mathrm{H} 2$.

Next, to test for changes in the behaviour of the younger female cohorts, column (2) presents the results obtained when interaction terms of the previous two covariates with an indicator variable for the last cohort (1996-2005) are added to the baseline specification. There is a noticeable reduction in two above-mentioned effects, particularly in the $\beta_{2}$ coefficient, pointing out to lower path dependence among younger female researchers. Finally, columns (3)-(4) report results when the interaction between fixed effects for fields and cohorts is also included. Although the size and statistical significance of the estimated coefficients are smaller than before, the qualitative results remain unaltered.

\subsection{Disentangling the origin of path dependence: GDC versus SE}

To distinguish between hypotheses $\mathrm{H} 1 \mathrm{~b}$ and $\mathrm{H} 1 \mathrm{c}$ in generating path dependence, we use a negative binomial (field) fixed-effects regression model (Cameron and Trivedi 1998). ${ }^{15}$ For H1b, the dependent variable is the number of male-researchers in each field and 5-year cohort $\left(\# \mathrm{M}_{f c}\right)$ while the main explanatory variable is a quadratic

\footnotetext{
14 A potential problem with the linear specification in (2) is that the dependent variable is between 0 and 1. To check how important this problem is, we also estimated a tobit regression model with both right and left censoring allowing for random effects [field fixed effects would lead to incidental parameters problem; cf. Greene (2008)]. The results, not reported for the sake of brevity, were qualitatively similar.

15 One of the referees pointed out to us a related paper by England et al. (2003), that we were not aware of, where a similar negative-binomial model is used to address the issue of changes in sex composition regarding doctorates awarded in the US in 18 major academic disciplines-ranging from natural sciences to
} 
Table 3 Determinants of female shares by fields and Ph.D. cohort

\begin{tabular}{lllll}
\hline Variables & $(1)$ & $(2)$ & $(3)$ & $(4)$ \\
\hline$Q_{\mathrm{fc}}$ & $-0.005^{* *}$ & $-0.009 * *$ & $-0.004 * *$ & $-0.006^{* *}$ \\
& $(0.002)$ & $(0.004)$ & $(0.002)$ & $(0.003)$ \\
$Q_{\mathrm{fc}} * \mathbf{1}(96-05)$ & - & $0.006^{*}$ & - & $0.002^{* *}$ \\
& & $(0.004)$ & & $(0.001)$ \\
$\mathrm{F}_{f c-\ell}$ & $0.547 * * *$ & $0.652^{* * *}$ & $0.489 * *$ & $0.589 * *$ \\
& $(0.068)$ & $(0.068)$ & $(0.072)$ & $(0.082)$ \\
$\mathrm{F}_{f c-\ell} \mathbf{1}(96-05)$ & - & $-0.234 * * *$ & - & $-0.276^{* *}$ \\
& & $(0.102)$ & & $(0.137)$ \\
$\mathrm{NA}$ & 0.012 & 0.009 & 0.011 & 0.0010 \\
& $(0.007)$ & $(0.008)$ & $(0.008)$ & $(0.009)$ \\
Field FE & Yes & Yes & Yes & Yes \\
Cohort FE & Yes & Yes & Yes & Yes \\
Field*Coh. FE & No & No & Yes & Yes \\
No. of Obs. & 272 & 272 & 272 & 272 \\
$\mathrm{R}^{2}$ & 0.199 & 0.253 & 0.228 & 0.275 \\
\hline
\end{tabular}

Asterisks denote level of significance: * 10\%, ** 5\%, *** 1\%. A dummy intercept for 1996-05 is also included

$F E$ fixed effects

polynomial in the fraction of females in that field in previous cohorts $\left(F_{f c-\ell}\right)$. It is assumed that $\# \mathrm{M}_{f c}$ follows a negative binomial distribution with expected value $\mu_{f c}^{M}$ and a variance given by $\mu_{f c}^{M}\left(1+\theta \mu_{f c}^{M}\right)$ where $\theta$ is the over-dispersion parameter ( $\theta=0$ corresponds to the Poisson distribution). In turn, the expected value $\mu_{f c}^{M}$ is assumed to be a function of explanatory variables $\left(\mathbf{x}_{\mathrm{fc}}\right)$, such that $\ln \mu_{f c}^{M}=\delta_{f}+\beta^{\prime} \mathbf{x}_{f c}$ where $\delta_{f}$ is an intercept controlling for all stable characteristics in each of the fields. The model also includes the total number on males in all fields in each cohort as an "offset" term for the dependent variable. The existence of decreasing and convex function in $F_{f c-\ell}$ will imply that there is a threshold of feminization in a given field beyond which men move to another field, in line with the $S E$ prediction.

As for H1c, in the spirit of the $G D C$ hypothesis, a similar negative binomial model has been estimated for the number of women in each field and 5-year cohort $\left(\# \mathrm{~F}_{\mathrm{fc}}\right)$. The "offset" term is now the total number of females in each cohort and the main control is the same as before, namely, a quadratic polynomial in $F_{f c-\ell}$ since, according to $G D C$, women chose fields where women are already present. $G D C$ would be consistent with an increasing function in $F_{f c-\ell}$. Convexity implies the existence of a minimum threshold in the female share beyond which women increasingly join that field. Concavity, in turn, could be interpreted as implying that women may start quitting these female-oriented fields once the female share exceeds a certain threshold, possibly due to decreasing marginal utility of competing only with women.

Footnote 15 Continued

social sciences and humanities — between 1971 and 1998. We postpone a brief discussion on the differences between their findings and ours to the end of this section. 
Table 4 Fixed-effects negative binomial regression models

\begin{tabular}{lll}
\hline Dependent vr. & Explanatory vrs. & \\
\cline { 2 - 3 } & $\%$ Fem. & $\begin{array}{l}\% \text { Fem } \\
\text { Squared }\end{array}$ \\
\hline No. of males $\left(\# \mathrm{M}_{\mathrm{fc}}\right)$ & & 1.343 \\
& -0.545 & $(1.010)$ \\
No. of females $\left(\# \mathrm{~F}_{\mathrm{fc}}\right)$ & $(0.532)$ & $-2.638^{* * *}$ \\
& $1.165^{* * *}$ & $(1.110)$ \\
\hline
\end{tabular}

Asterisks denote level of significance: * 10\%, ** 5\%, *** 1\%. All models include dummy variables for fields and either no. of male or female researchers in all fields, consistent with the dependent variable

Table 4 presents the estimated coefficients on the two key explanatory variables, $F_{f c-\ell}$ and its square. ${ }^{16}$ The most interesting finding is that, while these coefficients are not statistically significant for men, they are significant and yield an inverted U-shape shape for women. Thus, we interpret these results as supporting GDC (H1c) as the main source of path dependence. Indeed, simple calculations from the two reported coefficients in the second row of this Table show that, when the percent female of the field exceeds $22 \%$, additional increments deter women's entry.

Finally, it is worth noticing that this finding contrasts with the results obtained in the above-mentioned paper by England et al. (2003). Using a similar methodology to ours, these authors find that deterrence is larger for men than for women among the US population receiving doctorates in a wide range of academic fields between 1971 and 1998. This opposite finding may be explained by the fact that gender differences in the choice of doctorates could just closely reflect gender patterns observed in the choice bachelor's degrees where it might be easier for men to stigmatize female fields because of relatively low pay or other reasons (see Sax 2001). By contrast, we think that this type of stigmatization may be less plausible when dealing with the choice of subfields within a single discipline.

\subsection{Multinomial logit for individual field choices}

In this section, we report evidence about the modeling of the outcome probability that an individual chooses a given field. The most natural framework would be a multinomial logit where each individual has a choice of a single field to check if this choice is affected by the share of women already in that field or its quality index. Since there is more than one field per researcher this model cannot be used with RFs as the unit of analysis. Instead we identify the main field for each of the 1876 researchers in our sample (see Table 1). Moreover, due to the small number of women and the large

\footnotetext{
16 The estimates of the over-dispersion parameter, $\theta$, are 0.28 and 0.35 , respectively, both being significantly different from zero at 5\% level. Allison and Waterman (2002) have shown that the conventional standard errors of the estimated coefficients in negative binomial models with fixed effects suffer from downward bias. To correct for this bias, we have followed their suggestion of multiplying standard errors by the square root of the ratio of Pearson's Chi-square to the degrees of freedom.
} 
number of subfields (34) in the Econphd.net rankings, the multinomial logit has a problem in identifying separate effects for each subfield. This difficulty is smaller when using the shorter list of 10 JEL fields. Hence, the results reported below correspond to this coarser classification. The specification we consider is as follows:

$$
\begin{aligned}
\mathrm{P}_{i f c}= & \lambda^{\prime} x_{i f c}+\delta_{0} Q_{f c}+\delta_{1} Q_{f c}{ }^{*} \mathbf{1}(\mathrm{fem})+\delta_{2} Q_{f c}{ }^{*} \mathbf{1}(\mathrm{fem}) \\
& +\theta_{1} F_{f c-\ell} \mathbf{1}(96-05)+\theta_{0} F_{f c-\ell}(\mathrm{fem})+\theta_{2} F_{f c-\ell}{ }^{*} \mathbf{1}(\mathrm{fem}){ }^{*} \mathbf{1}(96-05)+\varepsilon_{i f c}
\end{aligned}
$$

where $\mathrm{P}_{i f c}$ is the outcome probability that an individual $i$ in cohort $c$ chooses field $f ; \boldsymbol{x}_{i f c}$ is a vector of individual-specific covariates which includes a gender dummy (fem $=1$ ), an indicator for 1996-2005, dummies for departments where they graduated and where they are affiliated in $2005,{ }^{17}$ plus cohort and field dummies, and their interaction. As in the aggregate specification (2), the female and last-cohort dummies have been interacted with the female shares and field quality indices.

Thus, positive coefficients $\left(\theta_{1}\right)$ on the first interaction term concerning $F_{f c-\ell}$ will provide indication that women care more than men about the share of female researchers working in a specific field, in line with the path dependence hypothesis. Likewise, a negative sign of the coefficients on the second double interaction term $\left(\theta_{2}\right)$ will indicate that path dependence decreases for the youngest female cohort. Similar arguments for $Q_{f c}$, albeit with $\delta_{1}<0$ and $\delta_{2}>0$, would yield support to $\mathrm{H} 2$ and a weaker effect for the last cohort, respectively.

Table 5 reports the results regarding the estimated $\theta^{\prime} \mathrm{s}$ and 's coefficients in the form of marginal effects at the individual level and then averaged. The coefficients on the field-quality score $\left(\delta_{1}\right)$ are generally positive. By contrast, the coefficients on the interaction term with the female dummy $\left(\delta_{2}\right)$ are mostly negative and especially significant for Econometrics, Micro/Theory and Macro. Yet, the coefficient on the triple interaction $\left(\delta_{3}\right)$ switches again to being positive. For example, an increase of 1 unit in the quality score of Econometrics (from an average of 0.571 to 0.581 ) lowers the probability of women doing research in that field by $0.007(=0.013-0.020)$, yet only by $0.003(=0.013-0.020+0.004)$ if they belong to the youngest cohort. As regards the share of women in a field, the positive estimated coefficients on the first interaction term $\left(\theta_{1}\right)$ supports path dependence in the majority of fields where the past proportion of women in higher (see Table 1). By contrast, the coefficients on the second interaction term $\left(\theta_{2}\right)$ are mostly negative.

\section{Concluding remarks}

In this paper, we have drawn some implications from various theories of segregation in order to explain differences in the distribution of research fields among academic men and women-economists, a rather novel topic in the gender literature. To do so, we have compiled a new database containing detailed information about fields of specialization

\footnotetext{
17 The indicator variables for current department and department of graduation try to capture different specialization by field across departments which may influence field choices. All departments at the graduation stage which are not included in the top-50 list are bundled in a single group.
} 


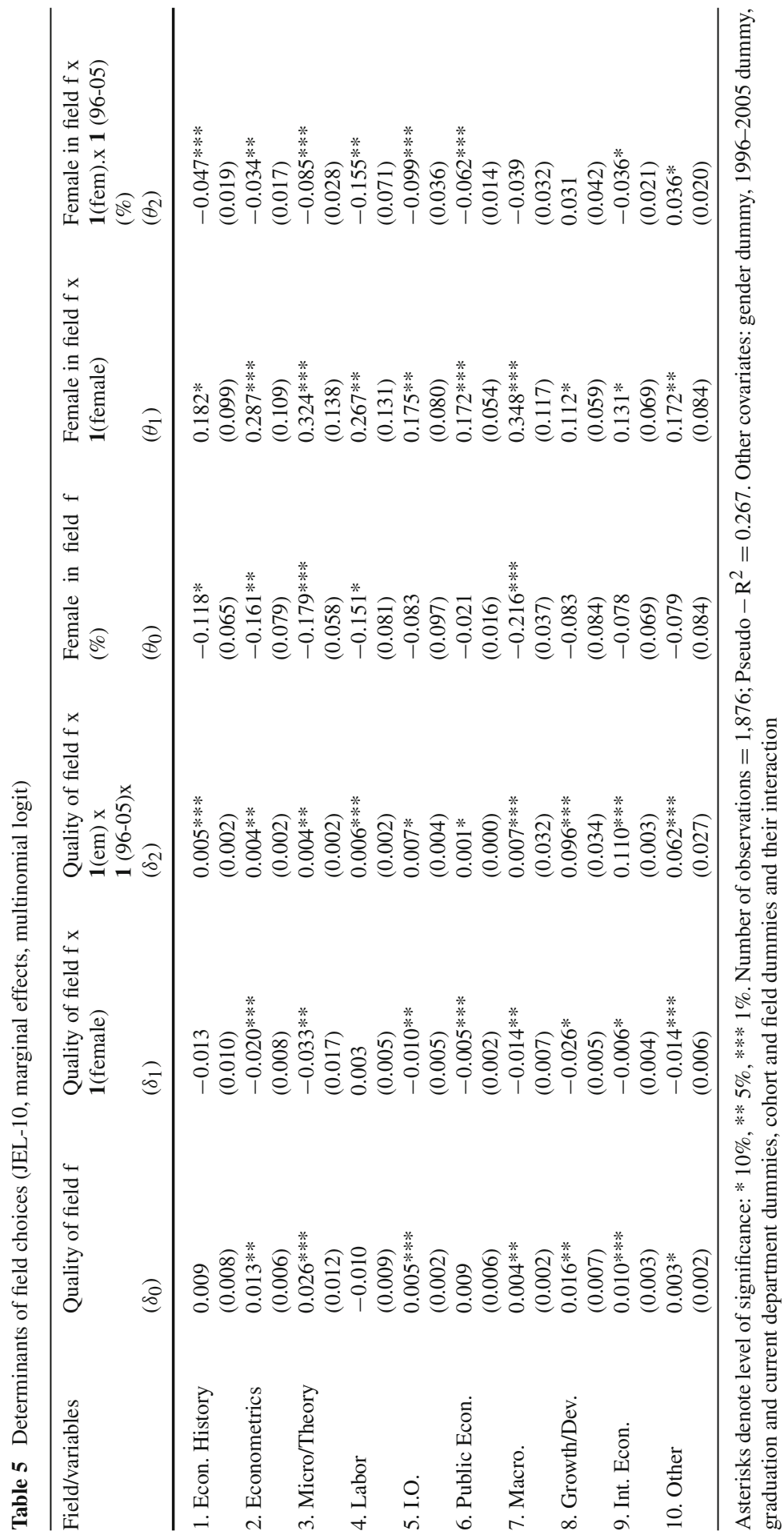


and other individual characteristics of the 2005 roster of economics faculty in the top50 economics departments in the world, according to the rankings on the Econphd website. The cross-section nature of our dataset gives rise to a non random truncation of the sample of researchers which should be borne in mind when interpreting results, though fragmentary comparative evidence with smaller panel data for a handful of top US departments confirms that the patterns we analyze are not just the outcome of sample biases. Further, it is important to keep in mind that the female faculty members of any of these top-50 departments are likely to be a very particular sample of women in terms if career orientation and attachment. Therefore they may not be fully representative of other women affiliated to average economics departments.

With these two caveats in mind, we document that there are large differences between men and women-economists in terms of research-field choices. Besides characterizing "female" fields, we analyze how gender segregation by field has developed across Ph.D. cohorts. Evidence is provided in favor of strong path-dependence in female choices, i.e., the probability that a woman-economist chooses a given field is positively related to the past share of women in that field. Although, we cannot fully discard that this persistent feature might be explained by women having different preferences than men regarding field choices, we argue that this phenomenon is better rationalized by women-economists avoiding male-dominated fields rather than by men-economists avoiding female-oriented fields. We also find that the female share in a given field is negatively related to an index of how competitive is that field (proxied by the proportion of papers in each field which are published in highly prestigious journals). Finally and foremost, our empirical evidence points out towards path dependence being much weaker among younger researchers, so that the gender gaps are slowly but steadily narrowing in many fields.

Many interesting issues remain to be addressed. For example: why does gender segregation of fields decline for the younger cohorts? None of the previous theories (PP, SE and GDC) would predict this outcome, unless preferences have changed or increasing competition in the academia has led women to enter male-dominated fields. Yet, at this stage this is only a conjecture. Also, it would be interesting to know directly from the faculty members in our sample which factors led them to choose a specific research fields. With this goal in mind, we have distributed a questionnaire to a matched sample (by cohort and departments) of men and women asking them about various reasons behind their choices (e.g., genuine social interest, expectations of academic or economic success, specialization of the department of origin, etc.) as well as some family circumstances at the time of completing their Ph.D. dissertations (civil status, number of children if any, etc.). We received replies from 125 female (i.e. $44 \%$ of our sample of women) and 122 male researchers. Although, analyzing how this information relates to the above-mentioned evidence is beyond the scope of this paper, we can preview a rather striking result: whereas $42.2 \%$ of women who graduated before 1985 chose a field for its "social interest" $(25.2 \%$ for men), this share has fallen to $32.8 \%$ (23.7\% for men) for those who graduated between 1996 and 2005. These responses are seemingly in line with our previous explanation of female initial field choices and the subsequent development towards less segregation. 


\section{Appendix A}

\section{See Table 6}

Table 6 List of Top 50 academic institutions (Econphd.net), \% of female faculty members and quality index in 2005

\begin{tabular}{|c|c|c|c|}
\hline & Department & Women (\%) & Qual. \\
\hline 1 & Harvard University & 15.4 & 210.7 \\
\hline 2 & University Chicago & 14.3 & 159.3 \\
\hline 3 & Massachusetts Institute of Technology (MIT) & 11.1 & 136.8 \\
\hline 4 & University California, Berkeley & 12.9 & 134.9 \\
\hline 5 & Princeton University & 16.7 & 118.3 \\
\hline 6 & Stanford University & 7.7 & 114.3 \\
\hline 7 & Northwestern University & 17.4 & 112.9 \\
\hline 8 & University Pennsylvania & 10.0 & 110.9 \\
\hline 9 & Yale University & 15.6 & 108.9 \\
\hline 10 & New York University & 7.1 & 105.1 \\
\hline 11 & University California, Los Angeles & 20.8 & 94.9 \\
\hline 12 & London School of Economics (LSE) & 16.1 & 94.9 \\
\hline 13 & Columbia University & 15.4 & 93.2 \\
\hline 14 & University Wisconsin, Madison & 17.6 & 69.5 \\
\hline 15 & Cornell University & 14.7 & 68.6 \\
\hline 16 & University Michigan, Ann Arbor & 21.5 & 68.0 \\
\hline 17 & University Maryland, College Park & 16.2 & 67.4 \\
\hline 18 & University Toulouse I (Sciences Sociales) & 10.4 & 65.3 \\
\hline 19 & University Texas, Austin & 10.3 & 62.1 \\
\hline 20 & University British Columbia & 13.3 & 61.6 \\
\hline 21 & University California, San Diego & 21.6 & 61.4 \\
\hline 22 & University Rochester & 17.4 & 58.0 \\
\hline 23 & Ohio State University & 10.3 & 57.7 \\
\hline 24 & Tilburg University & 9.1 & 56.8 \\
\hline 25 & University Illinois (Urbana-Champaign) & 7.9 & 56.6 \\
\hline 26 & Boston University & 9.7 & 56.0 \\
\hline 27 & Brown University & 10.3 & 52.8 \\
\hline 28 & University California, Davis & 25.0 & 49.3 \\
\hline 29 & University Minnesota & 20.0 & 48.8 \\
\hline 30 & Tel Aviv University & 8.3 & 48.0 \\
\hline 31 & Oxford University & 17.2 & 47.8 \\
\hline 32 & University Southern California & 8.7 & 46.7 \\
\hline 33 & Michigan State University & 21.6 & 45.1 \\
\hline 34 & Warwick University & 19.1 & 44.8 \\
\hline 35 & Duke University & 14.3 & 43.8 \\
\hline
\end{tabular}


Table 6 continued

\begin{tabular}{llrr}
\hline 36 & University Toronto & 15.3 & 42.5 \\
37 & University Amsterdam & 21.9 & 42.0 \\
38 & Penn State University & 22.2 & 41.9 \\
39 & University Cambridge & 23.8 & 38.6 \\
40 & Carnegie Mellon University & 15.8 & 38.0 \\
41 & University North Carolina - Chapel Hill & 12.9 & 37.8 \\
42 & Boston College & 17.9 & 37.3 \\
43 & California Institute of Technology (Caltech) & 12.5 & 37.3 \\
44 & Texas A\& M University & 17.6 & 37.0 \\
45 & European University Institute & 0.0 & 36.0 \\
46 & University Carlos III Madrid & 16.7 & 35.7 \\
47 & University College London & 8.6 & 35.3 \\
48 & University Essex & 25.6 & 34.8 \\
49 & Indiana University & 15.6 & 34.2 \\
50 & Hebrew University & 0.0 & 33.9 \\
\hline
\end{tabular}

\section{Appendix B}

See Table 7, Fig. 6

Table 7 Distribution of researchers by cohorts for each JEL-10 field

\begin{tabular}{|c|c|c|c|c|c|c|}
\hline \multirow[t]{2}{*}{ Field } & \multicolumn{6}{|l|}{ Ph.D. cohort } \\
\hline & Before 1965 & 1966-1975 & 1976-1985 & 1986-1995 & 1996-2005 & Total \\
\hline \multirow[t]{2}{*}{ 1. Econometrics } & 7 & 29 & 37 & 52 & 61 & 186 \\
\hline & .0 & 1 & 4 & 9 & 12 & 26 \\
\hline \multirow[t]{2}{*}{ 2. Micro/Theory } & 10 & 41 & 78 & 105 & 148 & 382 \\
\hline & 0 & 1 & 2 & 3 & 6 & 12 \\
\hline \multirow[t]{2}{*}{ 3. Macro } & 9 & 33 & 44 & 48 & 64 & 198 \\
\hline & 1 & 1 & 3 & 5 & 6 & 16 \\
\hline \multirow[t]{2}{*}{ 4. International } & 8 & 21 & 26 & 37 & 39 & 131 \\
\hline & 0 & 1 & 1 & 6 & 5 & 13 \\
\hline \multirow[t]{2}{*}{ 5. Public Econ. } & 8 & 30 & 43 & 38 & 48 & 167 \\
\hline & 1 & 2 & 6 & 15 & 11 & 35 \\
\hline \multirow[t]{2}{*}{ 6. Labor } & 4 & 24 & 27 & 32 & 44 & 131 \\
\hline & 1 & 7 & 8 & 17 & 19 & 52 \\
\hline \multirow[t]{2}{*}{ 7. I.O. } & 4 & 18 & 34 & 37 & 53 & 146 \\
\hline & 0 & 2 & 8 & 11 & 20 & 41 \\
\hline \multirow[t]{2}{*}{ 8. Growth/Dev. } & 10 & 24 & 31 & 35 & 37 & 137 \\
\hline & 1 & 3 & 3 & 6 & 9 & 22 \\
\hline \multirow[t]{2}{*}{ 9. Economic History } & 7 & 13 & 14 & 10 & 12 & 56 \\
\hline & 1 & 3 & 8 & 8 & 11 & 31 \\
\hline \multirow[t]{2}{*}{ 10. Other } & 16 & 69 & 81 & 83 & 93 & 342 \\
\hline & 2 & 4 & 7 & 13 & 12 & 38 \\
\hline
\end{tabular}

The upper figures are the total number of researchers while the lower figures are the number of female researchers 


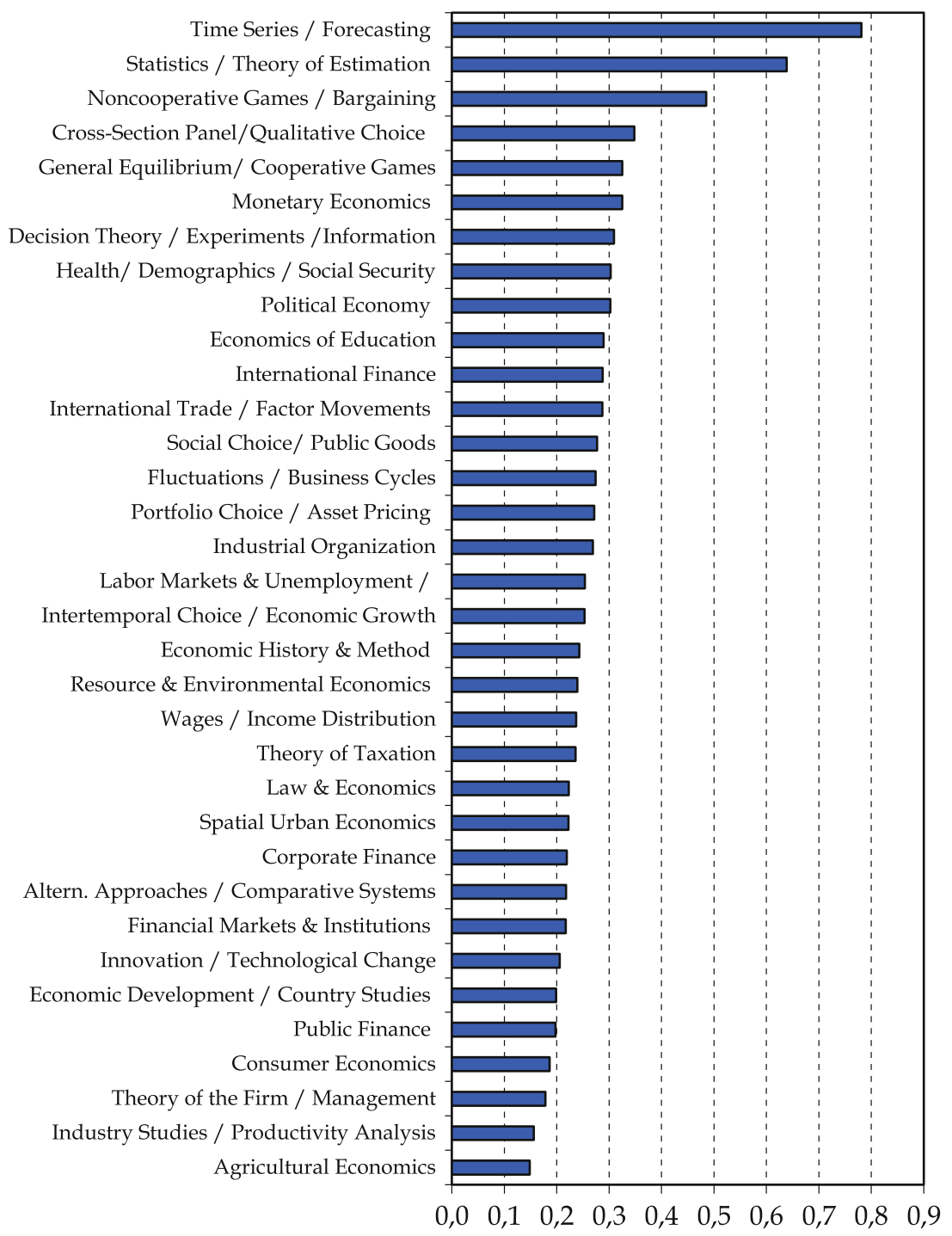

Fig. 6 Field quality scores (average across cohorts)

(I) The 10 fields chosen here correspond to the following aggregations of JEL codes:

Econometrics $\mathrm{C} 1-\mathrm{C} 5$, and $\mathrm{C} 8$,

Micro/Theory C0, C6, C7, C9 and D

\section{Macro E}

\section{International $\mathrm{F}$}


Public $\mathrm{H}$

Labor J

$I / O \mathrm{~L}$

\section{Dev/Growth O}

Econ. History B and N

Other A (General Economics and Teaching), G (Financial Economics), I (Health, Education and Welfare), K (Law and Economics), M (Business Economics), Q (Agricultural Economics), R (Urban and Regional Economics), and Z (Other Special Topics)

(II) The 20 fields correspond to the 19 main descriptors in JEL, where descriptor C has been disaggregated into C(1) (Mathematical and Quantitative Methods, and Game Theory) and C(2) (Econometrics, Programming and Data Collection)

(III) The 34 fields correspond to the descriptors in Econphd.net where there is an index of quality of publications. In terms of JEL descriptors they are defined as follows.

1. Economic History \& Method (A, B00-B49,N)

2. Alternative Approaches/Comparative Systems (B50-B59, P00-P59)

3. Statistics/Theory of Estimation (C00, C10-C16, C19, C20, C30, C40-C41, C44C45, C49)

4. Cross Section, Panel, Qualitative Choice Models (C21, C23-C29, C31, C33C39, C42-C43, C50-C52, C59, C80-C89)

5. Time Series/Forecasting (C22, C32, C53)

6. General Equilibrium Theory/Cooperative Games/Mathematical \& Comp. Economics (C60-C63, C65, C67-C69, C71, D50-D52, D57-D59, D84)

7. Noncooperative Games/Bargaining \& Matching (C70, C72-C73, C78-C79, D83)

8. Decision Theory/Experiments/Information Economics (C90-C93, C99, D00, D80-D82, D89)

9. Consumer Economics (D10-D12, D14, D18-D19, Z00, Z10-Z13)

10. Labor Markets \& Unemployment/Working Conditions/Industrial Relations (D13, J20-J23, J28-J29, J32-J33， J40-J45，J48-J49， J50-J54，J58-J59， J60J65, J68-J69, J80-J83, J88-J89, M50-M55, M59)

11. Wages/Income Distribution (D30-D31, D33, D39, J15-J16, J30-J31, J38-J39, J70-J71, J78-J79)

12. Health Care/Demographics/Social Security (I00, I10-I12, I18-I19, I30-I32, I38-I39, J00, J10-J14, J17-J19, J26)

13. Economics of Education (I20-I22, I28-I29, J24)

14. Theory of the Firm/Management (D20-D21, D23, D29, L20-L25, L29, L30L33, L39, M00, M10-M14, M19, M20-M21, M29, M30-M31, M37, M39, M40-M42, M49)

15. Industry Studies/Productivity Analysis (D24, L60-L69, L70-L74, L79, L80L86, L89, L90-L99)

16. Industrial Organization (D40-D46, D49, L00, L10-L16, L19, L40-L44, L49, L50-L52, L59) 
17. Innovation/Technological Change (O30-O34, O38-O39)

18. Social Choice Theory/Allocative Efficiency/Public Goods (D60-D64, D69, D70-D71, H00, H40-H43, H49)

19. Political Economy (D72-D74, D78-D79, H10-H11, H19)

20. Theory of Taxation (H20-H26, H29, H30-H32, H39)

21. Law \& Economics (K00, K10-K14, K19, K20-K23, K29, K30-K34, K39, K40K42, K49)

22. Intertemporal Choice /Economic Growth (D90-D92, D99, E20-E21, F40, F43, F47, F49, O40-O42, O47, O49)

23. Fluctuations/Business Cycles (E00, E10-E13, E17, E19, E22-25, E27, E29, E30-32, E37, E39)

24. Monetary Economics (E40-E44, E47, E49, E50-E53, E58-E59)

25. Public Finance (E60-E66, E69, H50-H57, H59, H60-H63, H69, H70-H74, H77, H79, H80-H82, H87, H89)

26. International Finance (F30-F36, F39, F41-F42)

27. International Trade/Factor Movements (F00-F02, F10-F19, F20-F23, F299

28. Economic Development/Country Studies (O00, O10-O19, O20-O24, O29, O50-O57)

29. Spatial, Urban Economics (R00, R10-R15, R19, R20-R23, R29, R30-R34, R38-R39, R40-R42, R48-R49, R50-R53, R58-R59)

30. Financial Markets \& Institutions (G00, G10, G14-G15, G18-G19, G20-G24, G28-G29)

31. Portfolio Choice/Asset Pricing (G11-G13)

32. Corporate Finance (G30-G35, G38-G39)

33. Resource \& Environmental Economics (Q00-Q01, Q20-Q21, Q24-Q26, Q28Q29, Q30-Q33, Q38-Q39, Q40-Q43, Q48-Q49)

34. Agricultural Economics (Q10-Q19, Q22-Q23)

\section{Appendix C}

See Table 8 


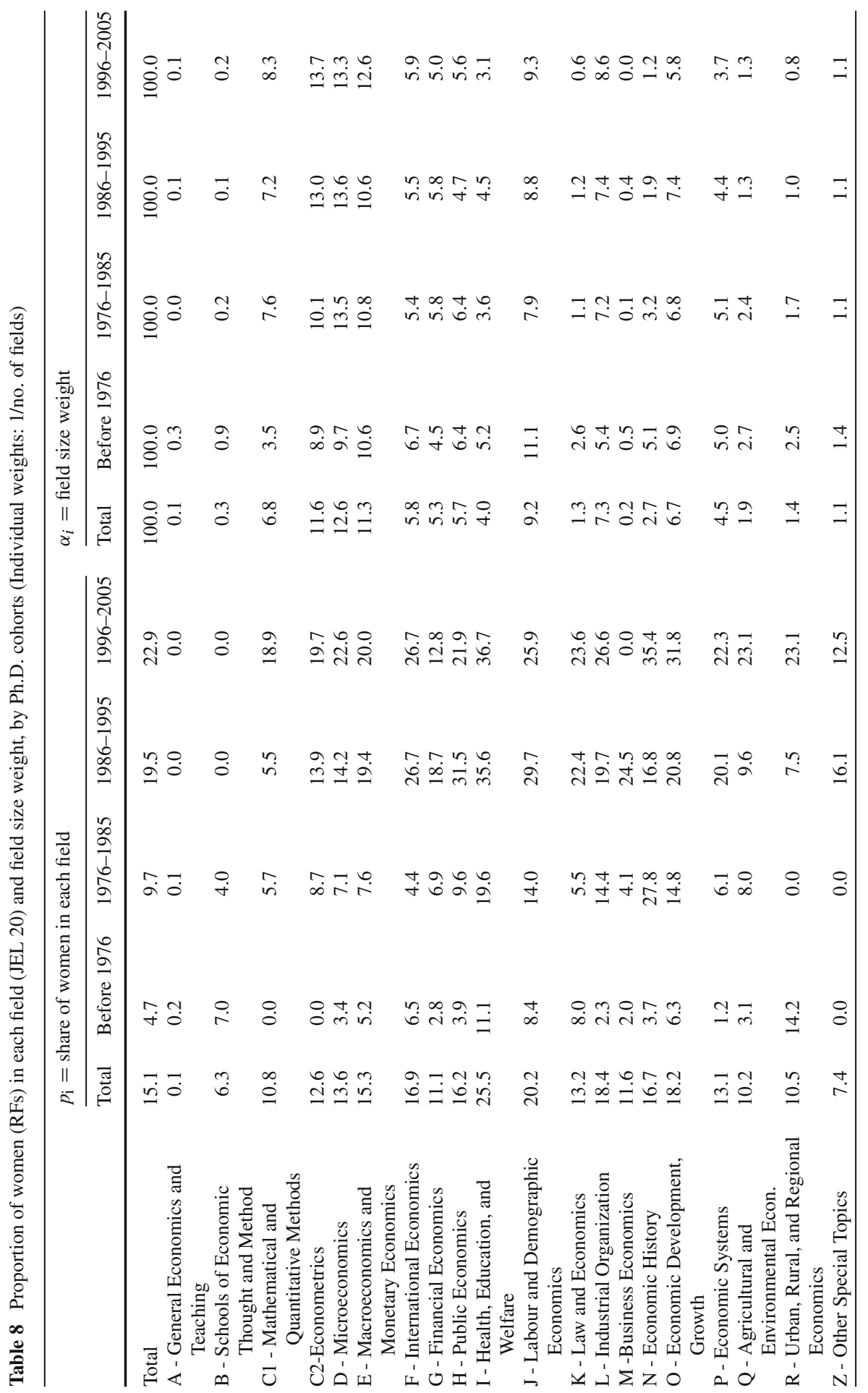


Open Access This article is distributed under the terms of the Creative Commons Attribution License which permits any use, distribution and reproduction in any medium, provided the original author(s) and source are credited.

\section{References}

Allison P, Waterman R (2002) Fixed-effects negative binomial regression models. In: Stolzenberg R (ed) Sociological methodology. Blackwell, Oxford

Bertrand M, Hallock K (2001) The gender gap in top corporate jobs. Ind Labor Relat Rev 55:3-21

Black S, Strahan P (2001) The division of spoils: rent-sharing and discrimination in a regulated industry. Am Econ Rev 91:814-831

Blau F, Kahn L (2000) Gender differences in pay. J Econ Perspect 14:75-99

Blau F, Simpson P, Anderson D (1998) Continuing progress? Trends in occupational segregation in the United States over the 1970s and 1980s. Fem Econ 4:29-71

Booth A, Burton J, Mumford K (2000) The position of women in UK academic economics. Econ J 110: 312-334

Borden V, Brown P, Majesky-Pullmann O (2007) Just the stats: top 100 disciplines by race and gender. (http://www.diverseeducation.com/artman/publish/article_8441.shtml)

Boschini A, Sjögren A (2007) Is team formation neutral: evidence from co-authorship patterns. J Labor Econ 25:325-365

Cameron AC, Trivedi PK (1998) Regression analysis of count data. Cambridge University Press, Cambridge

Dolado J, Felgueroso F, Jimeno JF (2001) Female employment and occupational changes in the 1990s: how is the EU performing relative to the US?. Eur Econ Rev 45:875-889

Dolado J, Felgueroso F, Jimeno JF (2004) Where do women work? Analyzing patterns in occupational segregation by gender. Ann Econ Stat 71(-72):293-315

England P, Allison P, Li S, Mark N, Thompson J, Budig M, Sun H (2003) Why are some academic fields tipping toward female? The sex composition of US fields of doctoral degree receipt, IPR WP-03-12

Ginther DK, Kahn S (2004) Women in economics: moving up or falling off the academic career ladder. J Econ Perspect 18:193-214

Gneezy U, Niederle M, Rustichini A (2003) Performance in competitive environments: gender differences. Q J Econ 118:1049-1074

Gneezy U, Rustichini A (2004) Gender and competition at young age. Am Econ Rev 94:377-381

Gneezy U, Leonard K, List J (2009) Gender differences in competition: evidence from a matrilineal and a patriarchal society. Econometrica 77:1637-1674

Goldin C, Rouse C (2000) Orchestrating impartiality: the impact of blind auditions on female musicians. Am Econ Rev 90:715-742

Greene W (2008) Econometrics Analysis, 6th edn. Prentice-Hall, Englewood Cliffs

Hamermesh DS (2005) An old male economist's advice to young female economists. CSWEP Newsletter, Winter

Hansen WL (1991) The education and training of economics doctorates. J Econ Lit 29:1054-1087

Kahn S (1993) Gender differences in academic career paths of economics. Am Econ Rev (P\&P) 83:52-56

Kahn S (1995) Women in the economics profession. J Econ Perspect 9:193-206

Kalaitzidakis P, Mamuneas T, Stengos T (2003) Rankings of academic journals and institutions in economics. J Eur Econ Assoc 1:1346-1366

Loury G (1977) A dynamic theory of racial income differences. In: Wallace PA, Lamond A (eds) Women, minorities and employment discrimination. Lexington Books, Lexington

McDowell JM, Singell LD, Ziliak JP (1999) Cracks in the glass ceiling: gender and promotion in the economics profession. Am Econ Rev (P\&P) 89:392-396

Niederle M, Vesterlund L (2007) Do women shy away from competition? Do Men compete too much? Q J Econ 122:1067-1101

Polachek S (1981) Occupational self-selection: a human capital approach to sex differences in occupational structures. Rev Econ Stats 63:60-69

Sax L (2001) Undergraduate science majors: gender differences in who goes to Graduate School. Rev High Educ 24:153-172

Schelling TC (1971) Dynamic models of segregation. J Math Sociol 1:143-186 